\title{
Configurações
}

Revista Ciências Sociais

\section{Fazer a ciência chegar mais longe: reflexões sobre o outreach universitário}

Making science go further: reflections on university outreach

Faire en sorte que la science aille plus loin : réflexions sur la vulgarisation scientifique

MARIA MANUEL VIEIRA, LIA PAPPÁMIKAIL e TATIANA FERREIRA

\section{OpenEdition}

Journals

\section{Edição electrónica}

URL: https://journals.openedition.org/configuracoes/14185

DOI: 10.4000/configuracoes. 14185

ISSN: 2182-7419

\section{Editora}

Centro de Investigação em Ciências Sociais

\section{Edição impressa}

Paginação: 27-42

ISSN: 1646-5075

\section{Refêrencia eletrónica}

MARIA MANUEL VIEIRA, LIA PAPPÁMIKAIL e TATIANA FERREIRA, «Fazer a ciência chegar mais longe: reflexões sobre o outreach universitário», Configurações [Online], 28 | 2021, posto online no dia 15

dezembro 2021, consultado o 28 dezembro 2021. URL: http://journals.openedition.org/configuracoes/ 14185 ; DOI: https://doi.org/10.4000/configuracoes.14185 
VIEIRA, Maria Manuel; PAPPÁMIKAIL, Lia; FERREIRA, Tatiana - Fazer a ciência chegar mais longe: reflexões sobre o outreach universitário. Configurações [em linha]. 28 (2021) p. 27-42.

\title{
Fazer a ciência chegar mais longe: reflexões sobre 0 outreach universitário
}

\author{
MARIA MANUEL VIEIRA* \\ Instituto de Ciências Sociais da Universidade de Lisboa \\ LIA PAPPÁMIKAIL** \\ Escola Superior de Educação do Instituto Politécnico de Santarém \\ TATIANA FERREIRA*** \\ Escola Superior de Educação do Instituto Politécnico de Santarém
}

\begin{abstract}
Resumo
Outrora ausente das prioridades das instituições do ensino superior, a divulgação de ciência para públicos não académicos tem ganho protagonismo nos últimos anos, e o chamado outreach tem-se multiplicado nas suas modalidades e públicos-alvo. Partindo da análise dos principais modelos e paradigmas de divulgação de ciência, perscruta-se neste artigo a amplitude e alcance do que é (ou deve ser) a "extensão universitária" e de como a sociologia se inscreve, em particular, nesse processo. A propósito da atividade "Estágios científicos de verão" para alunos do secundário dinamizada no OPJ/ ICS-ULisboa, reflete-se sobre as potencialidades, limites e desafios de iniciativas de promoção da educação e cultura científica para não académicos.
\end{abstract}

Palavras-chave: Sociologia, divulgação científica, públicos de ciência, ensino superior.

\section{Abstract \\ Making science go further: reflections on university outreach}

Once absent from the priorities of higher education institutions, science dissemination to non-academic audiences has gained prominence in recent years, and outreach activities have multiplied in its modalities and target audiences. Starting with the analysis of the main models and paradigms of science dissemination, this article explores the scope of what "university outreach" is (or should be) and how sociology fits into this process. Considering the activity "Scientific Summer Internships" for secondary school students

*E-mail: mmfonseca@ics.ulisboa.pt | ORCID ID: https://orcid.org/000-0002-25449694

**E-mail: lia.pappamikail@gmail.com | ORCID ID: https://orcid.org/0000-0003-1306-1059

***E-mail: tatiana.mjferreira@gmail.com| ORCID ID: https://orcid.org/0000-0003-1972-2575 
promoted by OPJ/ICS-ULisboa, we reflect on the potentialities, limits, and challenges of initiatives in promoting education and scientific culture for non-academics.

Keywords: Sociology, science outreach, science audiences, higher education.

\section{Resumé}

Faire en sorte que la science aille plus loin :réflexions sur la vulgarisation scientifique

Autrefois absente des priorités de l'enseignement supérieur, la diffusion de la science auprès de publics non universitaires a gagné en importance ces dernières années et les activités de vulgarisation scientifique se sont multipliées. En partant de l'analyse des principaux modèles et paradigmes de diffusion de la science, cet article explore l'amplitude et la portée de ce qu'est (ou devrait être) la «vulgarisation scientifique » et la manière dont la sociologie s'inscrit dans ce processus. Concernant l'activité « Stages scientifiques d'été » pour les lycéens promue par l'OPJ/ICS-ULisboa, nous réfléchissons au potentiel, aux limites et aux défis des initiatives visant à promouvoir l'éducation et la culture scientifique pour les publics non universitaires.

Mots-clés: Sociologie, diffusion scientifique, publics des sciences, enseignement supérieur.

\section{Introdução}

No momento em que escrevemos estas linhas assistimos, talvez pela primeira vez à escala mundial, à "ciência em direto". Com efeito, a emergência de um vírus altamente contagioso, potenciado por uma intensa mobilidade à escala global, provocou uma súbita situação pandémica que fez saltar para a opinião pública a importância do conhecimento científico e dos seus protagonistas, cuja tematização diária e insistente pelos media não deixa de colocar questões em torno dos modos de divulgação da(s) ciência(s). O próprio tema deste número da revista parece fazer eco desses debates, focando-se desta feita na Sociologia como matriz disciplinar a interrogar.

Este artigo pretende, a partir de um lugar institucional - um instituto de investigação em Ciências Sociais - e de uma experiência de disseminação científica - a iniciativa estágios de verão para alunos do ensino secundário dar contributos para a reflexão sobre a divulgação da Sociologia no contexto da academia. Divulgar ciência não é um dado definido de uma vez por todas: ele condensa significados plurais, cuja aplicação pode revelar ambiguidades e equívocos que importa analisar.

Inicia-se o artigo com uma breve viagem pela sociogénese do processo de divulgação científica e apresentação dos diferentes paradigmas que a enquadram. Aborda-se, depois, a especificidade da sociologia no que concerne o diálogo entre ciência e sociedade e convocam-se argumentos polissémicos acerca 
dos contributos que a sociologia pode oferecer à sociedade, a propósito dos diferentes paradigmas de divulgação utilizados. A análise de um estudo de caso de divulgação da sociologia realizado no Instituto de Ciências Sociais da Universidade de Lisboa com públicos escolares permite, nessa sequência, produzir algumas considerações sobre potencialidades e limites (institucionais e individuais) da extensão universitária dirigida a perfis específicos de interlocutores. Conclui-se sublinhando alguns dos desafios identificados.

\section{Fazer ciência, divulgar ciência}

Até meados do séc. XX, a chamada divulgação científica constitui uma atividade esparsa e avulsa a que alguns cientistas, muito poucos, se dedicam de forma voluntarista. $\mathrm{Na}$ verdade, até então a divulgação dos produtos de ciência para públicos não académicos e não escolares está ausente das missões atribuídas às instituições de ensino superior. Em Portugal como alhures, estas dedicam-se quase exclusivamente à produção e comunicação de ciência (entre pares) e à sua transmissão às novas gerações (ensino).

Os acontecimentos da II Guerra Mundial e seus efeitos irão, todavia, espoletar um aceso debate sobre a Ciência e promover um questionamento público acerca dos impactos sociais dos seus produtos. A responsabilidade social da ciência emerge como temática entre a comunidade científica, abrindo caminho para novas abordagens didáticas e epistemológicas.

Sem pretender esgotar as propostas surgidas durante todo este período refira-se como exemplo, ao nível do ensino, o chamado movimento CTSCiência, Tecnologia e Sociedade desenvolvido a partir dos anos 1970 no mundo anglo-saxónico com o propósito de "abordar temas e conceitos de C\& T inseridos em contextos reais, sociais, dando, assim, sentido funcional aos conceitos canónicos" (Martins, 2020, p. 18).

Por sua vez, no plano da produção de conhecimento, começa lentamente a emergir a necessidade de se consagrar uma maior atenção à promoção da cultura científica junto de um público alargado, com o intuito de aumentar a implantação da ciência na sociedade, tornar a ciência democraticamente mais acessível e dotar os indivíduos de ferramentas de interpretação do mundo que lhes permitam exercer a sua cidadania de forma mais informada. Um primeiro passo nesse sentido é dado através de iniciativas inspiradas no que se designa como Public Awareness of Science (PAS), um modelo e perspetiva de divulgação de ciência que visa uma "consciencialização", ou seja, a promoção de uma certa "sensibilidade para a ciência" (Costa, 2020, p. 40).

Não obstante as efervescentes iniciativas de educação popular ocorridas no período pós 25 de Abril de 1974 (Melo, 1981), no início da década de 1990 a prática da divulgação científica para o grande público está longe de ser abraçada pela maioria dos investigadores a trabalhar em Portugal. Num inquérito 
realizado em 1993 a uma amostra representativa de cientistas do setor público verifica-se que, no que toca à análise da prática científica, ou seja, às tarefas em que se decompõe o trabalho exercido, a dimensão de divulgação científica está ausente. Apenas se descobre, mais à frente no estudo citado, uma referência à avaliação pelos inquiridos da "dimensão de difusão e de controlo de conhecimento", que inclui o item "prática de divulgação científica", globalmente pouco valorizado (Jesuíno, 1995, p. 59-64).

A partir da $2^{\text {a }}$ metade da década de 1990 , um conjunto de fatores converge para uma mudança sensível deste cenário.

Por um lado, a União Europeia intensifica a aposta da relação entre ciência e cidadãos no contexto das políticas para a ciência, sobretudo a partir do $5^{\circ}$ Programa Quadro (1998-2002), o que determina a existência de financiamento destinado a projetos nessa área (Conceição, 2015). Por outro lado, é incontestável a importância de que se reveste, no caso português, o pensamento e a ação governativa de José Mariano Gago ${ }^{1}$ no recém-criado Ministério da Ciência e da Tecnologia, em 1995. O lançamento do programa Ciência Viva, em 1996, com efeitos duradouros até ao presente, impulsiona decisivamente a promoção da cultura científica e gera uma rede ativa de relações entre ciência e sociedade. Igualmente, a criação dos Laboratórios Associados em 1999, cuja missão deverá incluir a promoção da cultura científica, robustece esta dimensão. O surgimento de várias associações científicas, o crescimento da comunidade dos "mediadores de conhecimento" e a paulatina emergência de Gabinetes de Comunicação associados às instituições de investigação e ensino superior vão por sua vez alargando, na sociedade, o espectro de iniciativas dedicadas à divulgação da produção de ciência (Amorim e Santos, 2015). Entrados neste milénio, um estudo de 2014 confirma o aumento das práticas de comunicação pública de ciência na generalidade das unidades de I\&D, o que faz supor um envolvimento efetivo destes centros na promoção da compreensão pública da ciência (Entradas, 2015).

Este reconhecimento da importância da divulgação científica cresce a par do surgimento de outros modelos e paradigmas de outreach, a somar ao já referido public awareness of science (PAS). Acompanhando os avanços de escolarização e literacia dos públicos, o public understanding of science (PUS) (Costa, 2020) centra-se numa concepção lata de compreensão (de ciência) que pode envolver a compreensão de conteúdos, de processos, ou mesmo de fatores sociais a que a ciência não está imune (nomeadamente, interesses políticos e económicos) e que podem influenciar o rumo do que é (ou não) pertinente investigar. No limite, esta concepção admite o próprio questionamento público (opinião pública) das consequências do conhecimento científico (Stengers, 
2000) como elemento relevante de compreensão de ciência - ela mesma, um produto social. Neste caso, está-se muito próximo da fronteira com o modelo de outreach conhecido como public engagement with science and technology (PEST); trata-se de uma conceção que inclui "a própria participação pública em investigação científica", conferindo ao público de ciência um papel mais ativo no processo que não o de mero "consumidor de conteúdos de divulgação científica" (Costa, 2020, p. 63).

A noção de "ciência cidadã" representa uma amplificação do modelo PEST, associando essa participação ao exercício de um direito de cidadania. Os fundamentos dessa modalidade participada de comunicação entre ciência e públicos, que inspira o plano de ação específico Science with/for Society do programa H2020, estão explicitados no documento “Dez princípios-chave da ciência cidadã” elaborado pela European Citizen Science Association (2015). Vejamos como estes modelos se traduzem na divulgação da Sociologia, e que desafios podem trazer.

\section{Produzir Sociologia, divulgar Sociologia}

É sabido que a Sociologia é uma ciência institucionalmente recente em Portugal (Machado, 1996, 2009; Pinto, 2010), tornada possível com a instauração democrática em 1974, pelo que a temática da divulgação, no que concerne o saber sociológico, também o será. Não obstante, pela sua própria natureza enquanto ciência social, ela dialoga permanentemente com a sociedade, o seu núcleo central de interesse. Fá-lo por duas vias, constitutivas da especificidade desta ciência: dialoga com os sujeitos da pesquisa, participantes na produção de dados graças ao acionamento de técnicas de investigação que os mobilizam; e dialoga por via dos próprios objetos de pesquisa, dado os produtos da investigação sociológica frequentemente questionarem - e, nessa medida, interferirem - (n)a vida social.

Assim, a institucionalização da Sociologia no país não somente inaugurou esse diálogo, como também foi gradualmente promovendo o reconhecimento público de uma expertise que, a par de outras ciências sociais com mais tradição no espaço público - a Economia, ou a Ciência Política - foi sendo requisitada com mais ou menos frequência, quer no campo profissional não académico, quer no quadro do apoio a políticas públicas.

No caso da solicitação da Sociologia em apoio a políticas públicas, constata-se, pelo menos em regimes democráticos, que os decisores políticos tendem a legitimar as suas opções em evidências sustentadas no conhecimento científico. O diálogo com o poder político é, pois, uma outra dimensão da relação da Sociologia com a sociedade. Mas a sua abordagem não é unânime. Um autor como Burawoy $(2004$, p. 259) sugere que o que classifica como policy sociology estará sujeita a instrumentalização, uma vez que "serve um fim específico 
definido por um cliente com o qual o sociólogo tem uma relação contratual real ou fictícia”. Já para outros autores, como A. Santos Silva (2017), que advogam uma perspetiva menos instrumental (e instrumentalizável) da Sociologia, como preconizado no Código Deontológico (1992) dos sociólogos portugueses, trata-se de oferecer à ação política os recursos reflexivos próprios desta ciência: "a nossa ciência não perde necessariamente a sua matriz e arsenal reflexivos e não se torna inelutavelmente "instrumental" quando trabalha no quadro das políticas públicas institucionais" (Silva, 2017, p. 784). Por outras palavras, o contributo nuclear da Sociologia - como, de resto, da Ciência em geral - reside na sua capacidade problematizadora (Silva, 2017).

O que estará em causa, nesta como noutras modalidades de intervenção sociológica no espaço público, é a própria definição e grau de abrangência do que se considera ser "intervenção", enquanto exercício de cidadania protagonizado por cientistas. Os modelos de divulgação de ciência atrás enunciados não são inócuos, nem estão ao abrigo de controvérsias sobre a legitimidade e limites de cada fórmula; neste caso, observa-se a transferência, para o debate sobre a divulgação da Sociologia, de argumentos já conhecidos nas disputas - pluriparadigmáticas - sobre a sua produção. Um dado é, porém, inquestionável: para além das referidas áreas de atuação, a divulgação da sociologia tem granjeado interesse por parte de alguns sociólogos que trabalham na academia e o chamado outreach é hoje um campo vasto de atuação, aberto a múltiplas interpretações.

Por um lado, o desenvolvimento das tecnologias de informação e comunicação alargou consideravelmente o espectro de formatos de intervenção daqueles profissionais no espaço público (em ambiente virtual, nomeadamente) para além dos média tradicionais (jornais, revistas, rádio, televisão) onde alguns têm presença regular. Muitas destas intervenções são palco para a divulgação de resultados de pesquisas sobre questões/problemas sociais que, transformados em problemas sociológicos, desvendam facetas que questionam o que se julga saber, expandindo os recursos disponíveis para a ação social - na linha do public awareness of science - e, nessa medida, revelam o contributo que o conhecimento científico pode oferecer como recurso de cidadania.

Uma outra perspetiva da ciência como exercício de cidadania encontra-se patente em alguns dos projetos e atividades promovidos por sociólogos provenientes ou não da academia, em estreita parceria com entidades, associações e grupos sociais na identificação e resolução de problemas locais baseadas na abordagem problem-solving learning com as comunidades, como advoga o movimento da ciência cidadã (ECSA, 2015), em sintonia com o public engagement with science and technology. Aliás, segundo alguns autores, esse seria mesmo o propósito de todo o trabalho sociológico: o de constituir uma tentativa de resposta a uma procura social (Castel, 2002). 
Ora, será porventura aqui que uma maior polissemia sobre o que a sociologia e a sua prática pode significar se manifesta. Os debates sobre o que é a public sociology, ou mesmo a distinção, no seu seio, entre a elite or traditional public sociology, marcada pelo carácter sociologicamente mediado do diálogo ciência-sociedade e a grassroots or organic public sociologies, caracterizado pela des-mediação desse diálogo (Burrawoy, 2004); a diferença entre "sociologia social", pautada por disposições militantes nas práticas de intervenção e "sociologia experimental", pautada por disposições de criatividade científica alicerçada no terreno de intervenção (Lahire, 2002); ou ainda, a apologia da utilidade sociológica do próprio engajamento, enquanto "instrumento para alargar o espaço mental da inquirição, o campo das questões colocadas" (Corcuff, 2002, p. 192) são exemplos das disputas presentes na arena sociológica e demonstram a amplitude de entendimentos sobre o que é (ou deve ser) a "extensão universitária".

Importa não esquecer neste elenco de atuações aquele que, impulsionado pela criação da Agência Ciência Viva, visa a promoção da educação e cultura científicas junto dos mais novos. Sublinhe-se que as Ciências Sociais estão envolvidas neste programa desde o seu lançamento em 1998, uma vez que dois Laboratórios Associados (o Centro de Estudos Sociais, da Universidade de Coimbra e o Instituto de Ciências Sociais, da Universidade de Lisboa) integram os seus associados fundadores. Talvez também por isso, algumas das iniciativas propostas pelo programa, inspiradas na abordagem do public understanding of science, tenham recebido a adesão destas instituições, no que foram acompanhadas por outras, igualmente dedicadas ao ensino e investigação em Sociologia (Conceição et al., 2008).

Qualquer que seja a modalidade de divulgação da Sociologia, o desafio era - e continua a ser - de ordem comunicacional: dialogar com públicos diferentes a partir do seu saber, estando permanentemente aberto ao seu questionamento.

\section{A divulgação científica (em Sociologia): reflexões a propósito de um estudo de caso}

Como ficou patente, as atividades de promoção e divulgação da cultura científica foram sendo progressivamente acolhidas pelas instituições de ensino superior portuguesas e pelos seus centros de investigação, quer por pressão interna (aposta explícita do Ministério da Ciência), quer por influência externa (consagração por parte das políticas de ciência europeias e seu impacto nos critérios de avaliação das instituições de I\&D). A partir deste milénio, tais atividades foram assumidas como ingrediente da aferição do impacto social do conhecimento científico. Na última avaliação de instituições I\& D candidatas a Laboratórios Associados da FCT, um dos três pilares de apreciação consistia, justamente, na sua "contribuição para políticas públicas que respondam 
a desafios científicos, de saúde, ambientais, culturais, sociais, económicos ou políticos" (FCT, 2020). Por seu turno, de entre os critérios concernentes aos "produtos/outputs" a prever em muitas das atuais candidaturas para financiamento nacional ou europeu de projetos, as iniciativas com "impacto social" tendem a ser requisito obrigatório.

Não obstante, a promoção da educação e cultura científicas fora de muros pode enfrentar alguns desafios. A partir de uma experiência duradoura de divulgação da Sociologia junto de públicos escolares num Laboratório Associado - o Instituto de Ciências Sociais da Universidade de Lisboa - em que as autoras têm participado, reflete-se sobre algumas das potencialidades e limites deste propósito, tanto a nível institucional, como a nível da Sociologia ${ }^{2}$.

\subsection{Divulgação da cultura científica junto de públicos escolares}

Enquanto instituição comprometida com o Programa Ciência Viva desde a sua génese, a missão de divulgar e comunicar ciência, cumprindo o objetivo de estender o conhecimento científico à comunidade (proposição, como se viu, ambígua e que pode ser operacionalizada mobilizando diferentes princípios e entendimentos do que constitui, de facto, este desígnio) foi abraçada desde cedo pelo Instituto de Ciências Sociais da Universidade de Lisboa, nomeadamente graças ao voluntarismo dos seus primeiros Observatórios ${ }^{3}$.

Estes grupos/programas de investigação têm procurado promover, de múltiplas formas, uma relação mais próxima com o público, numa ótica de serviço público. Esta relação tem-se materializado em iniciativas de disseminação e divulgação, disponibilizando recursos diversos nos seus websites, produzindo publicações dirigidas a públicos não académicos, elaborando estudos e informação útil para a definição de políticas, participando em projetos de pesquisa-ação, para além de intervenções regulares no espaço público mediático.

Para além destas atividades mais convencionais, um dos Observatórios (OPE/OPJ) envolveu-se com mais regularidade na dinamização de iniciativas de divulgação das Ciências Sociais, com particular destaque da Sociologia, junto de públicos escolares. Um público que, apesar de familiarizado com conhecimento científico canónico no seu quotidiano - através dos saberes escolares inscritos no currículo e legitimados em manuais, onde não há em regra

2 Para a análise que se segue, para além do património de experiência de cerca de 15 anos de coordenação, organização e dinamização dos estágios, cuja participação constitui um espaço privilegiado de observação participante, as autoras recorrem aos registos disponíveis desta experiência, ainda que não sistemáticos (relatórios anuais, listagem de candidatos, monitores e temas trabalhados, resultados dos projetos desenvolvidos, fichas de avaliação).

3 O OPJ-Observatório Permanente da Juventude, desde 1989, que aglutina em 2010 o então existente Observatório Permanente de Escolas-OPE; e o OBSERVA-Ambiente, Território e Sociedade, surgido em 1996. Mais tarde, em 2010, são criados no ICS três outros Observatórios: das Famílias e de Políticas de Família; da Qualidade da Democracia e o Instituto do Envelhecimento (ver https://www.ics.ulisboa.pt/observatorios/abertura). 
lugar para a controvérsia -, tem menos acesso à forma como esse conhecimento é construído, muitas vezes encerrada nos bastidores daquilo que é comunicado/ transmitido. Os jovens estudantes do ensino básico e secundário, classificáveis pela forma como se relacionam com a ciência como "iniciados", na tipologia de Costa et al. (2002), foram tornados, por esta entre outras razões, um público estratégico do referido Observatório.

Não obstante as iniciativas de disseminação protagonizadas pelo OPE/ OPJ com comunidades escolares que envolvessem outras atividades, de caráter mais pontual ${ }^{4}$, destacamos, neste artigo, a experiência de dinamização de estágios científicos de verão pela sua regularidade, longevidade e abrangência. Entre 2004 e 2019 (excetuando 2011 e 2012), realizaram-se um total de 37 estágios envolvendo 155 jovens do ensino secundário de diversas regiões do país. Estudantes de cursos científico-humanísticos, vocacionados para o prosseguimento de estudos de nível superior, estes estagiários provinham tendencialmente da área de línguas e humanidades, mas também das demais (ciências e tecnologias, ciências socioeconómicas e artes visuais).

O objetivo desta iniciativa identificou-se com os propósitos do public understanding of science: pretendeu-se "proporcionar a alunos de escolas secundárias públicas experiências de investigação no domínio científico das ciências sociais" enquanto prática que permitisse "induzir nos jovens o gosto pela cultura científica, familiarizá-los com modalidades de produção e produtos da ciência e treinar as suas competências críticas" (OPE/OPJ).

Em linha com o princípio de dar a conhecer o ofício de cientista social, e beneficiando do facto de os estágios ocorrerem num Instituto que agrega investigadores de várias Ciências Sociais, procurou garantir-se alguma diversidade disciplinar. Muito embora a Sociologia tenha tido um lugar de destaque (com 22 estágios), ao longo dos anos dinamizaram estágios investigadores na área da Antropologia (5), Psicologia Social (4), História (2), Ciência Política (3) e Economia (1). Considerando as catorze edições da iniciativa, e mesmo tendo em conta ajustamentos às circunstâncias de cada edição, os estágios científicos desenvolvidos no ICS obedeceram transversalmente a algumas linhas mestras, definidoras de uma certa práxis explicitamente perseguida. A proposta consistia no seguinte: selecionados a partir de candidaturas nas escolas com as quais o OPE/OPJ estabelecera "parcerias de geminação científica" ou inscritos na plataforma da Agência Ciência Viva, conforme os casos, os estudantes participantes, divididos em pequenos grupos, eram acompanhados no ICS por um investigador da casa durante uma semana, em horário laboral completo (manhã e tarde), beneficiando da envolvente de uma instituição de ensino superior, em instalações e recursos. Cada monitor, dentro da sua área de interesse e investigação - mobilizando não raras vezes os seus projetos em 
curso -, propunha e desenvolvia ao longo da semana com os estudantes um pequeno exercício de investigação, numa lógica de aprendizagem experiencial (Kolb, 1984). Aprender fazendo constituía o mote, seguindo os passos e as "regras do método" - da construção do problema ao resultado, passando pela leitura teórica, escolha de técnicas de recolha e tratamento da informação, com deslocações ao terreno, sempre que necessário.

Globalmente, enquanto experiência educativa não formal, a proposta estava sobretudo centrada no processo, a experimentação das várias etapas do procedimento científico, e não tanto no produto final, ainda que dos micro projetos de investigação resultassem relatórios e apresentações públicas dos resultados - ou não fosse a disseminação e o confronto com os pares um ingrediente fundamental da produção de conhecimento científico. No espaço de uma semana, portanto, mimetizavam-se todos os passos e etapas, não excluindo os expectáveis obstáculos e adversidades, num concentrado de experiências e vivências. Tal era possível dado a abordagem estar ancorada a uma lógica de proximidade (Breviglieri, 2005), assente em pequenos grupos, de 3/4 estudantes no máximo, com valor intrínseco em termos de aprendizagem. Esta opção estratégica foi condição para um acompanhamento permanente à progressão dos participantes e ao esclarecimento de dúvidas surgidas no percurso de busca pelo saber: afinal, questionar é não só o ato inaugural de qualquer investigação científica, como o gesto que a alimenta, em todas as fases do processo de construção do conhecimento. O princípio inerente à metodologia proposta pressupunha, pois, a existência de tempo e espaço para a interação individualizada, e em larga medida informal, favorecendo o à-vontade para interpelar a realidade e o outro.

É importante sublinhar que, nestes estágios, a aproximação à ciência se fazia também através da aproximação ao cientista, em regra investigadores mais jovens, cooptados para a "missão" de comunicar ciência. Atendendo ao ambiente interativo vivido nestes estágios e à avaliação extremamente positiva da relação com os monitores, é possível colocar a hipótese de que a ausência de experiência docente, por parte significativa dos monitores, pode ter constituído uma mais valia, ao facilitar o contraste diferenciador desta atividade com as dinâmicas hierárquicas subjacentes à forma escolar e ao distanciamento geracional (e simbólico) presente na tradicional relação professor-estudante (Pappámikail e Vieira, 2017). Mais, não raras vezes os investigadores-monitores eram eles próprios estudantes de doutoramento, é certo, ou em fase de desenvolvimento do seu percurso formativo pós-doutoral, facto que seguramente facilitou o esbatimento das resistências dos jovens à abordagem informal, mas substantiva do ponto de vista dos conteúdos e competências, que o mundo adulto que a Universidade constitui lhes oferecia naquele momento.

A avaliação bastante positiva com que habitualmente o estágio era pontuado no final pelos jovens não impede que, da parte dos seus dinamizadores, 
se tenham identificado alguns desafios processuais na aprendizagem experiencial da Sociologia. Por um lado, são referidas as dificuldades em ultrapassar as conhecidas armadilhas colocadas pela familiaridade com o social à compreensão dos fenómenos sociais, distinguindo problemas sociais de problemas sociológicos. A abundância das múltiplas e contraditórias "sociologias dos atores", amplificadas pelos média e pelas redes sociais, tão frequentadas por jovens adolescentes, coloca desafios acrescidos ao exercício de distanciamento reflexivo constitutivo da ciência, necessário às "sociologias profissionais" (Corcuff, 2002). Por outro, são apontados os obstáculos que se prendem com a tarefa de aprofundamento teórico através da leitura de literatura especializada, tão penosa quanto fundamental para a mediação científica, exercício de uma forma geral acolhido com pouco entusiasmo.

Não obstante, para os cientistas envolvidos ao longo dos anos, uma das mais-valias destes estágios, além da promoção de uma maior sensibilidade para o questionamento crítico do mundo social, tem sido proporcionar aos públicos escolares o contacto com backstage regions (Goffman, 1959) da ciência. Experimentar o tempo de produção de conhecimento e as suas vicissitudes (as dificuldades de construir um problema, o tempo das leituras, os saberes subjacentes à elaboração de instrumentos de recolha de informação, os contratempos da sua aplicação no terreno, os desafios da análise de dados, as relações sociais de (não)cooperação no interior das equipas de pesquisa, para mencionar alguns dos processos vividos nos estágios) revela uma outra faceta do conhecimento - a aventura da descoberta.

\subsection{A disseminação, os públicos e os critérios de investimento acadé- mico e institucional}

O acolhimento de iniciativas de divulgação do conhecimento por parte das instituições de ensino superior é hoje uma realidade. Existirão várias justificações louváveis para essa adesão institucional, mas não são também de descartar razões de natureza instrumental. No que concerne às atividades para públicos escolares, para além da grandeza inerente à missão de promover a educação científica junto dos mais novos, a dinamização de iniciativas como os estágios de verão contribui também para o engrandecimento reputacional da IES promotora.

Ainda assim, as circunstâncias podem não ser propícias a algumas dessas iniciativas. Partindo do exemplo em análise, nos últimos anos a equipa de coordenação no ICS tem-se deparado com dificuldades na mobilização de jovens monitores para esta atividade, resultando na diminuição do número de estágios oferecidos. A indisponibilidade de tempo a despender com esta iniciativa no formato habitual (uma semana em horário completo) manifestada por potenciais monitores, contraria a lógica de mentoria e de proximidade pretendidas, 
obrigando, ou à fragmentação do formato num somatório de "módulos" sucessivos de disponibilidades, ou ao recurso a jovens bolseiros remunerados pelos Observatórios para garantir a semana de estágio. Isto apesar do entusiasmo e da satisfação com a experiência, expressivamente demonstrada pelos monitores nos relatórios de avaliação produzidos nos primeiros anos desta iniciativa e que para efeito deste artigo pudemos revisitar. Importa entender as suas causas, pelo que iremos, de forma exploratória, avançar com algumas hipóteses.

Por um lado, recorde-se, a acrescida valorização económica e social do conhecimento que se observou nos últimos anos em Portugal e na Europa fez surgir, nas instituições de ensino superior, estruturas dedicadas à comunicação e divulgação de conhecimento e iniciativas por elas realizadas. Assiste-se, assim, ao alargamento de iniciativas e, em alguns casos, a uma certa replicação, autónoma, de atividades dinamizadas pelo programa Ciência Viva com recurso a investigadores daquelas instituições. Exemplo disso é a iniciativa "Verão na ULisboa"5, uma proposta de experiência para públicos escolares semelhante à dos estágios Ciência Viva, realizada anualmente desde 2014 pela Universidade de Lisboa com o apoio das suas unidades orgânicas (entre as quais o ICS). Esta multiplicação concorrencial de iniciativas aumenta as necessidades de monitores. Se as instituições de ensino superior com cursos de formação inicial dispõem anualmente, no âmbito de áreas curriculares com vertente prática, de uma potencial bolsa de jovens estudantes para dinamizar este tipo de ativida$\mathrm{des}^{6}$, os centros de investigação sem oferta de ensino graduado, como o ICS, vêm a sua capacidade de recrutamento limitada.

Esta questão não pode ser dissociada das dinâmicas que hoje atravessam a academia e que se impõem de forma crescente àqueles que a habitam ditando, num clima altamente concorrencial, o primado da produção e da produtividade científica. O diktat publish or perish assombra hoje as instituições de ensino superior, e a produtividade científica, medida em publicações, representa para muitos o único garante da permanência/sobrevivência no campo ou da existência de oportunidades de trabalho, mesmo que em regime de precariedade. Os próprios concursos para entrada (e progressão) na carreira dão esse claro sinal à navegação, ao atribuir percentagens distintas às dimensões de "Investigação", "Ensino" e "Extensão Universitária” a exibir pelos candidatos, o que condiciona o investimento que os mesmos estão na disposição de realizar em cada domínio. Assim, a disseminação do conhecimento produzido, um elemento omnipresente na retórica normativa que enforma o diálogo entre ciência (e quem a produz) e a sociedade, revela-se, no caso do trabalho com os públicos

5 Cf. https://www.ulisboa.pt/info/verao-na-ulisboa.

6 Exemplo disso são os Debates "Olhar Sociológico" nas Escolas Secundárias, dinamizados por alunos de licenciatura. https://aps.pt/pt/debates-nas-escolas-secundarias-perspectiva-sociologica-sobre-o-mundo/ 
escolares, em geral pouco atrativo para quem ambiciona (e precisa) acumular CVs academicamente "úteis".

Uma última questão prende-se com os propósitos da divulgação científica. Será lícito supor que, para determinados membros da academia, o grau de adesão a atividades de divulgação científica dependerá do formato, alcance e públicos envolvidos: uns interlocutores valerão mais do que outros, e para alguns, os públicos de um ensino "menor" - o pré-superior - constituirão uma "pura perda de tempo" (Almeida e Vieira, 2006). Dois tipos de propósitos podem ser identificados. Por um lado, num contexto de forte concorrência académica, a mediatização da ciência, potenciada pelas plataformas digitais, tem vindo a ser valorizada enquanto palco por excelência de construção de visibilidade, reputação e renome no espaço público, a que alguns sociólogos se têm dedicado com grande disponibilidade e protagonismo (Vieira et al., 2020). Neste caso, trata-se de um outreach que, para alguns, não deixa de conter um propósito instrumental de reconhecimento público, com potenciais vantagens profissionais presentes e/ou futuras. Por outro lado, a extensão universitária adquire igualmente relevância quando se transmuta em prestação de serviços à comunidade sob a forma de estudos por encomenda (diagnósticos, avaliação) financiado por decisores políticos, entidades privadas ou do terceiro sector, uma vez que constituem fonte de financiamento para investigadores e suas equipas, e também para as instituições (na figura de overheads). "A capacidade de diversificar as fontes de financiamento (...)" é, significativamente, o segundo dos três pilares de avaliação das instituições de I\& D candidatas a Laboratório Associado FCT (FCT, 2020).

\section{Conclusão}

Neste tex to comprova-se o crescente reconhecimento social da importância da divulgação científica, traduzido em múltiplas propostas e modalidades operativas: desde o inaugural public awareness of science, traduzido numa abordagem top-down da relação entre o cientista-especialista e o público-leigo a que se dirige, até às modalidades mais próximas e cooperativas como propõem o public understanding of science e o public engagement with science and technology.

No caso específico da Sociologia, se o diálogo entre ciência e sociedade é constitutivo do fazer sociológico, a sua divulgação coloca particulares desafios, em função dos horizontes de entendimento do conceito - e relações com a própria ciência matricial - adotados. De facto, os limites do que se considera ser divulgação de conhecimento não deixa de questionar os próprios limites da intervenção sociológica. Não deixando a sociologia de ser uma prática social, uma eventual clonagem do sociólogo a partir do(s) interlocutor(es) com quem interage e suas causas (políticas, económicas, ou de outra natureza), dispensando os procedimentos mediados da ciência, pode conduzir ao 
empobrecimento do espaço de possibilidades problematizadoras, e/ou à sua instrumentalização, reduzindo "a nova versão do mundo social assim produzida como a (única) verdade (possível) sobre o mundo social” (Lahire, 2002, p. 50).

A divulgação da Sociologia pela academia é também condicionada pelas dinâmicas em curso no en sino superior. Um estudo de caso sobre uma iniciativa de promoção da cultura científica dirigida a públicos escolares numa IES permitiu apurar u ma constelação de impactos, não detetáveis à escala macro: o tipo de dificuldades que se colocam à apreensão sociológica por parte dos destinatários da divulgação; as prioridades de investimento (temporal) em atividades de ex tensão universitária, face a outras tarefas, decorrentes da primazia conferida à produção científica; a hierarquização de palcos e de públicos onde e a quem comunicar ciência, em função dos propósitos de gestão da carreira - ou do acesso à mesma.

Qualquer que seja a modalidade de educação e divulgação científica utilizada, a aproximação das populações à ciência está longe de ser tarefa fácil ou isenta de contradições. O conhecimento científico — não obstante a sua omnipresença - tornou-se fortemente especializado e complexo, dependente do trabalho de profissionais altamente qualificados a operar em organizações também elas muito especializadas. A comunicação destas organizações com o exterior tem os seus problemas próprios, desde logo devido à dificuldade de articulação entre as linguagens dominantes no campo científico, no meio escolar, nos média ou na vida quotidiana em geral; mas, também, dadas as crescentes exigências às quais estas instituições estão sujeitas, a uma relativa falta de recursos específicos para iniciativas de promoção da cultura científica ou ainda, não será descabido dizê-lo, à resistência que uma parte da academia ainda coloca ao envolvimento nestas atividades (Conceição et al., 2008, p. 53).

\section{Referências bibliográficas}

ALMEIDA, Ana Nunes; VIEIRA, Maria Manuel - A escola em Portugal. Lisboa: Imprensa de Ciências Sociais, 2006. ISBN : 978-972-671-181-0.

AMORIM, Catarina; SANTOS, Júlio Borlido - Uma história da comunicação de ciência. In ASSOCIAÇÃO PORTUGUESA DE SOCIOLOGIA - Código Deontológico. Lisboa: APS, 1992.

RODRIGUES Maria de Lurdes; HEITOR, Manuel (orgs.) - 40 anos de políticas de ciência e de ensino superior. Coimbra: Almedina, 2015. ISBN: 9789724061214. p. 467-502.

BREVIGLIERI, Marc-Bienfaits et méfaits de la proximité dans le travail social. In ION, Jacques, (ed.) - Le travail social en débat(s). Paris : La Découverte, 2005. ISBN : 978-2707144409. p. 219-34.

BUR AWOY, Michael - The world needs public sociology. Sosiologisk Tidsskrift. Noruega. ISSN : 0804-0486. 12 (2004), p. 255-272.

CASTEL, Robert - La sociologie et la réponse à la demande sociale. In LAHIRE, Bernard (ed.) - À quoi sert la sociologie ? Paris : La Découverte, 2002. ISBN: 978-2707135667. p. 67-77. 
CONCEIÇÃO, Cristina - Promoção de cultura científica: ação política e mobilização. In RODRIGUES Maria de Lurdes; HEITOR, Manuel (orgs.) - 40 anos de políticas de ciência e de en sino superior. Coimbra: Almedina, 2015. ISBN : 9789724061214. p. 429-466.

CONCEIÇÃO, Cristina; GOMES, Maria do Carmo; PEREIRA, Inês; ABRANTES, Pedro; COSTA, António Firmino da - Promoção de cultura científica: Experiências da sociologia. Sociologia: Problemas e Práticas. Lisboa. 57 (2008), p. 51-81.

CORCUFF, Philippe - Sociologie et engagement: nouvelles pistes épistémologiques dans l'après-1995. In LAHIRE, Bernard (ed.) - À quoi sert la sociologie? Paris: La Découverte, 2002. ISBN: 978-2707135667. p. 175-194.

COSTA, António Firmino; ÁVILA, Patrícia; MATEUS, Sandra - Públicos da Ciência em Portugal. Lisboa: Gradiva, 2002. ISBN: 978-972-662-871-2.

COSTA, Ilídio Monteiro - Ciência cidadã: envolvimento do público na investigação e divulgação em astronomia. Porto: Universidade do Porto, 2020. Tese de doutoramento.

ENTRADAS, Marta - Envolvimento societal pelos centros de I\& D. In RODRIGUES, Maria de Lurdes; HEITOR, Manuel (orgs.) - 40 anos de políticas de ciência e de ensino superior. Coimbra: Almedina, 2015. ISBN: 9789724061214. p. 503-516.

EUROPEAN CITIZEN SCIENCE ASSOCIATION - Dez princípios da ciência cidadã, 2015 [em linha] [consult. 19 fev. 2021]. Disponível em: http://doi.org/10.17605/OSF.IO/XPR2N.

FCT (Fundação para a Ciência e a Tecnologia) - Evaluation guide for the award of the "title" and of "complementary base funding" of "associate laboratories [em linha], 2020. [consult. 19 fev. 2021]. Disponível em: https://www.fct.pt/apoios/unidades/docs/EvaluationGuide_ LaboratoriosAssociados.pdf.

GAGO, José Mariano - Homens e ofícios. Lisboa: Espaço Ulmeiro Associação Cultural e Associação Portuguesa para a Cultura e a Educação Permanente, 2020. ISBN: 978-989-54901-0-3.

GOFFM AN, Erving - The presentation of self in everyday life. New York: Doubleday Anchor Books, 1959. ISBN : 10. 9780385094023.

JESUÍNO, Jorge Correia (coord.) - A comunidade científica portuguesa nos finais do séc. XX. Oeiras: Celta, 1995. ISBN: 9728027265.

KOLB, David - Experiential Learning: experience as the source of learning and development. Englewood Cliffs: Prentice Hall, 1984. ISBN : 9780132952613.

LAHIRE, Bernard - Utilité: entre sociologie expérimentale et sociologie sociale. In LAHIRE, Bernard (ed.) - À quoi sert la sociologie ? Paris: La Découverte, 2002. ISBN : 978-2707135667. p. 43-66.

M ACH ADO, Fernando Luís - Meio século de investigação sociológica em Portugal: uma interpretação empiricamente ilustrada. Sociologia. Porto. ISSN: $\quad$ 0872-3419. 19 (2009), p. 283-343.

M ACH ADO, Fernando Luís - Profissionalização dos sociólogos em Portugal: contex tos, recomposições e implicações. Sociologia: Problemas e Práticas. Lisboa. ISSN 0873-6529. 96. 20 (1996), p. 43-103.

MARTINS, Isabel - Revisitando orientações cts|ctsa na educação e no ensino das ciências. A PEduC Revista/ A PEduC Journal. ISSN : 2184-7436. 1: 1 (2020), p. 13-29 [em linha]. [consult. 16 fev. 2021]. Disponível em: https://apeducrevista.utad.pt/index.php/apeduc/article/ view/63/1.

MELO, Alberto - Educação de adultos: conceitos e práticas. In SILVA, Manuela; TAMEN; Maria Isabel (coord.) - Sistema de ensino em Portugal. Lisboa: Fundação Calouste Gulbenkian, 1981. p. 355-382.

PAPPÁM IKAIL, Lia, VIEIRA, Maria Manuel - A (in)disponibilidade dos sujeitos como objeto de estudo: reflexões a partir de duas pesquisas com adolescentes. In FERREIR A, Vítor Sérgio 
(org.) - Pesquisar jovens: Caminhos e desafios metodológicos. Lisboa: Imprensa de Ciências Sociais, 2017. ISBN : 978-972-671-453-8. p. 33-56.

PIN TO, José Madureira - A note on the evolution, the specificity and the social relevance of Portuguese sociology. Sociologia Online. Lisboa. ISSN: 1647-3337. 1 (2010), p. 1-11 [em linha] [consult. 16 fev. 2021]. Disponível em: https://revista.aps.pt/pt/revista-no-1/.

SILVA, Augusto Santos - Sociologia e política pública: sobre avanços recentes em Portugal. Análise Social. Lisboa. ISSN: 2182-2999. 225 LII: 4 (2017), p. $782-803$ [em linha] [consult. 16 fev. 2021]. Disponível em: http://analisesocial.ics.ul.pt/documentos/n225a03.pdf.

STENGERS, Isabelle - Les sciences et la lutte contre l'opinion. NAQD : Revue d'Etudes et de Critique Sociale. Argélia. ISSN : 1111-4371. 1 : 13 (2000), p. 33-45.

VIEIRA, Maria Manuel; DIOGO, Ana Maria; M ARQUES, Ana Paula - Ética e deontologia no exercício da Sociologia: Novos desafios. Sociologia O nline. Lisboa. ISSN: 1647-3337. 23 (2020) [em linha], p. $31-50$ [consult. 17 fev. 2021]. Disponível em: https://revista.aps.pt/pt/ revista-no-23/.

- Receção: 27.05.2021

- Aprovação: 14.06.2021 